\title{
Subareolar breast abscess in male patients: a report of two patients with a literature review
}

\author{
Takashi Kazama ${ }^{\text {* }}$ (D, Isao Tabei ${ }^{1}$, Chikako Sekine², Naotake Funamizu², Shinji Onda', Tomoyoshi Okamoto', \\ Hiroshi Takeyama ${ }^{3}$ and Toshiaki Morikawa ${ }^{3}$
}

\begin{abstract}
Background: Subareolar breast abscess (SBA) is a rare infectious disease of the breast in male patients.

Case presentation: Herein, we report two male patients with SBA. Patient 1 was initially diagnosed with a malignant tumor based on imaging findings; ultrasonography revealed a hypoechoic mass with blood flow. Patient 2 was diagnosed with inflammatory changes to his nipple; ultrasonography findings supported the diagnosis with an irregular hypoechoic mass with blood flow. Both patients received a cytological or histological biopsy preoperatively, which showed an abscess without malignant cells.

Conclusion: These cases serve as an important reminder to consider complete resection of the tumor including the responsible mammary duct (tumor and duct resection (TDR)) for curative therapy of SBA.

Keywords: Breast abscess, Breast tumor, Duct resection, Smoking, Recurrence, Fine needle aspiration, Retro-areolar, Zuska's disease
\end{abstract}

\section{Background}

A subareolar breast abscess (SBA) is an infected lump that occurs in the subareolar area. In 1951, Zuska et al. [1] first reported SBA, which is also known as Zuska's disease, as lactiferous fistulas. SBA has some properties that are recurrent and can lead to the formation of intractable fistulas. Although SBA is frequently encountered in female patients, it rarely occurs in male patients. To our knowledge, only nine case reports of SBA in male patients have been published to date. We herein describe two patients of SBA and provide a review of the literature.

\section{Case presentation Patient 1}

A 38-year-old man was referred to our institute with a mass in his right breast with nipple discharge. He had no significant medical history. He had a smoking history

\footnotetext{
* Correspondence: jr_tks@yahoo.co.jp

${ }^{1}$ Department of Surgery, Jikei University Daisan Hospital, 4-11-1,

Izumihoncho, Komae City, Tokyo 201-8601, Japan

Full list of author information is available at the end of the article
}

of 15 cigarettes per day for 15 years. A physical examination revealed an elastic, soft, and mobile mass in the right subareolar region. Ultrasonography revealed a hypoechoic lesion, measuring $16 \mathrm{~mm}$, with accompanying posterior echo attenuation, irregular borders, and blood flow (Fig. 1). Moreover, the internal echo pattern of the mass was heterogeneous. As these findings were highly suggestive of a malignant tumor, an ultrasonography-guided core needle biopsy (CNB) was performed. The CNB findings showed no evidence of malignancy, but they revealed inflammatory cells including lymphocytes (Fig. 2). Based on the above findings, the patient was diagnosed with SBA, and tumorectomy was performed under local anesthesia. Histological examination of the tumor revealed granulation of the tissue with inflammatory changes and a lack of neoplastic changes and evidence of malignancy.

As the abscess recurred 8 months after the operation, the patient underwent an additional complete resection under local anesthesia. The patient has had no recurrence for 1 year and 10 months after the second operation. 


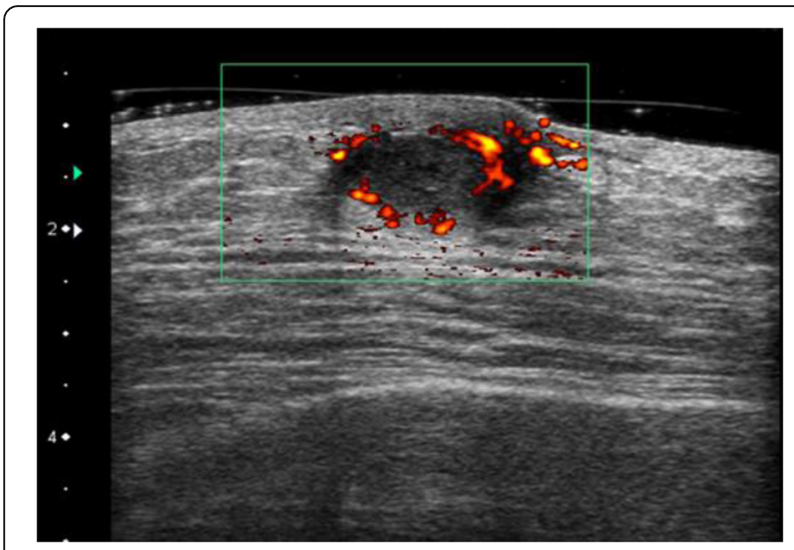

Fig. 1 Ultrasonography revealed a hypoechoic lesion $16 \mathrm{~mm}$ in size, with accompanying posterior echo attenuation and blood flow. These findings were highly suggestive of a malignant tumor

\section{Patient 2}

A 65-year-old man consulted a local doctor upon noticing a hard mass with skin inflammation in his right breast. At that time, his diagnosis was mastitis and he received an oral antibacterial agent (ampicillin $1500 \mathrm{mg} /$ day) for 14 days. Although the abscess temporarily had shrunk, it grew again 3 months later. He was then referred to our institution for further treatment. His medical history consisted of diabetes, surgery for colon carcinoma, and chronic hepatitis $\mathrm{C}$. He also had a smoking history of 25 cigarettes per day for 40 years. On admission, his physical examination revealed a $20-\mathrm{mm}$ hard mass in the subareolar region. An inflammatory change to the skin on the right lower breast portion under the nipple was observed (Fig. 3). Ultrasonography demonstrated a hypoechoic lesion measuring $20 \mathrm{~mm}$, with an irregular border, blood flow, and a heterogeneous internal echo pattern (Fig. 4). Fine needle aspiration (FNA) showed evidence of an abscess, and the

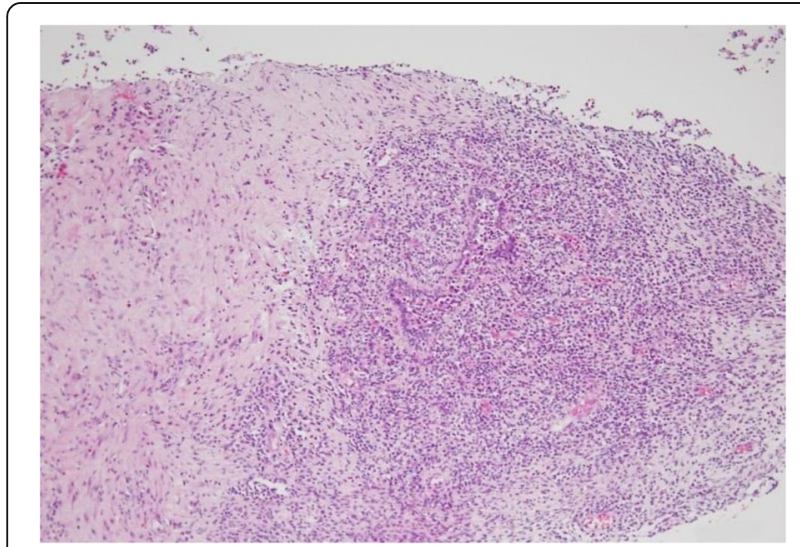

Fig. 2 CNB showed lymphocytes and infiltration of primarily inflammatory cells. There was no evidence of malignancy

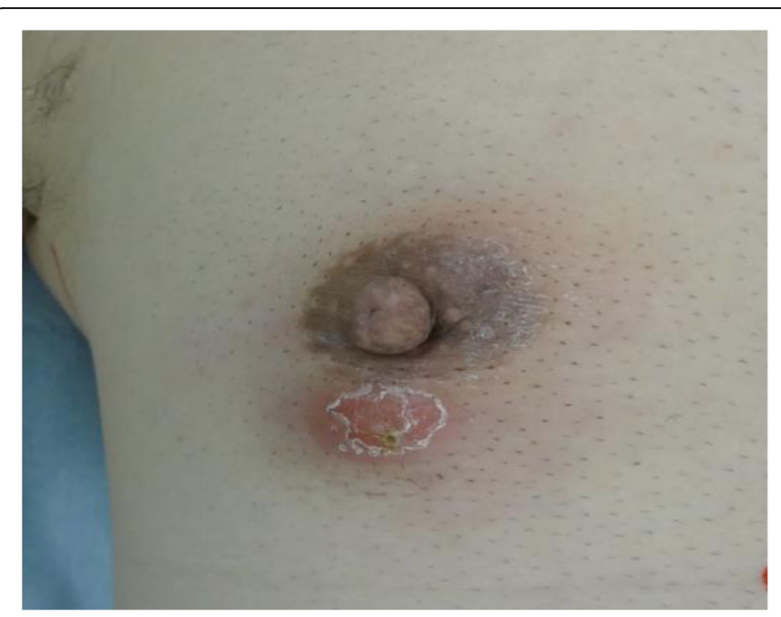

Fig. 3 The skin around the nipple was red and inflamed

diagnosis was SBA. To obtain curative therapy, tumor and duct resection (TDR) was performed under general anesthesia to remove the effected ducts completely (Fig. 5). The duct tracked from the abscess was identified as the effected duct and was excised along to a nipple as possible. A histological examination revealed neutrophilbased inflammatory cell infiltration and inflammatory granulation of the tissue, which was lacking neoplastic changes (Fig. 6). The diagnosis was consistent with SBA. At present, he has no evidence of recurrence for 2 years and 3 months since the surgery.

\section{Discussion}

SBA was first established as an infection that was distinct from mastitis in 1951 by Zuska et al. [1] regardless of their gender. The pathogenesis of SBA was thought to include the formation of a keratin embolus from the squamous metaplasia of the ductal epithelium; the

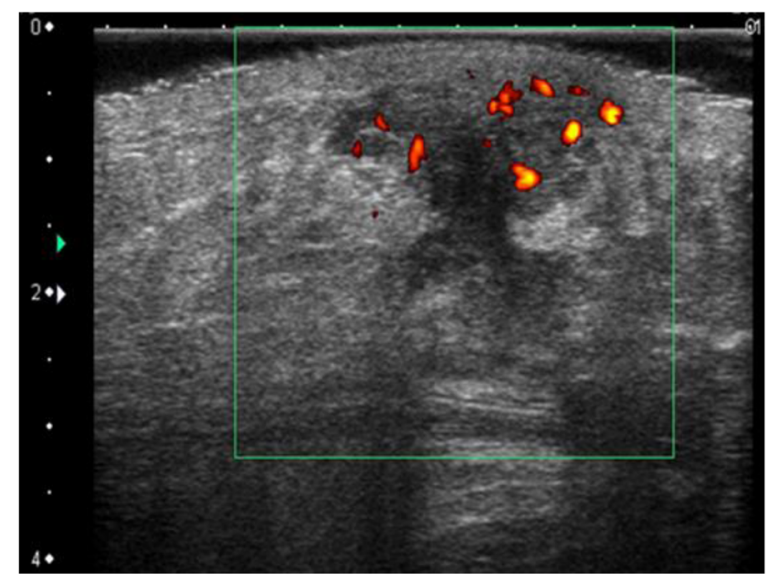

Fig. 4 Ultrasonography revealed a hypoechoic lesion $20 \mathrm{~mm}$ in size, with border irregularity and blood flow, initially diagnosed malignancy suspected 


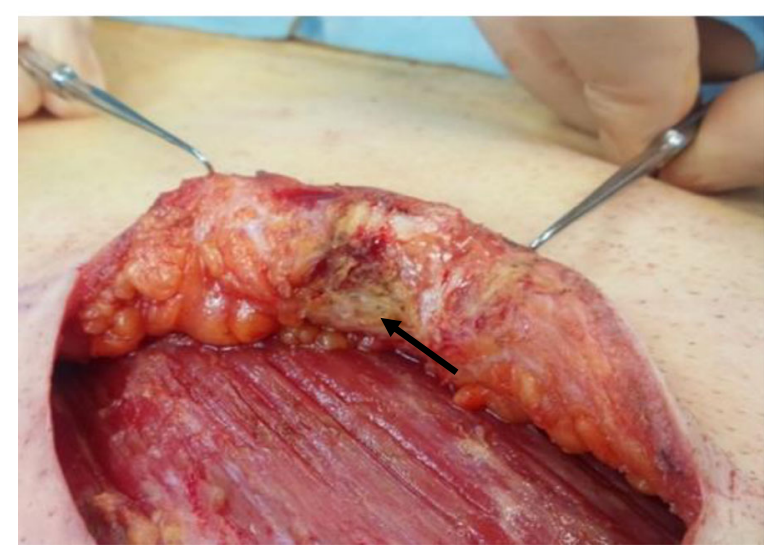

Fig. 5 TDR was performed to completely remove the effected ducts and the areolar lesion. The arrow shows the margin of the subareolar mammary duct

keratin embolus expands the mammary duct, and an abscess and a fistula were formed by bacterial invasion [2]. On the other hand, follicular obstruction of the pilosebaceous unit had also been pointed out as one of causes; furthermore, there were no unified views on the pathogenesis of a SBA [3-6]. In both patients that we experienced, squamous metaplasia was not observed pathologically. Smoking, diabetes mellitus, obesity, nipple piercing, or nipple inversion has been suggested as a risk factor for SBA [7, 8]. The relationship between smoking and SBA seems particularly strong; Bundred et al. reported that breast abscesses containing anaerobic bacteria were significantly more likely to occur in current smokers than in non-smokers. Both patients were heavy smokers; the abovementioned is likely to apply. Upon diagnosis of this disease, in patient 1, ultrasonography presented findings of malignancy, and CNB was performed. Generally, SBA shows no specific findings [9]. Peifen et al. described the utility of high-

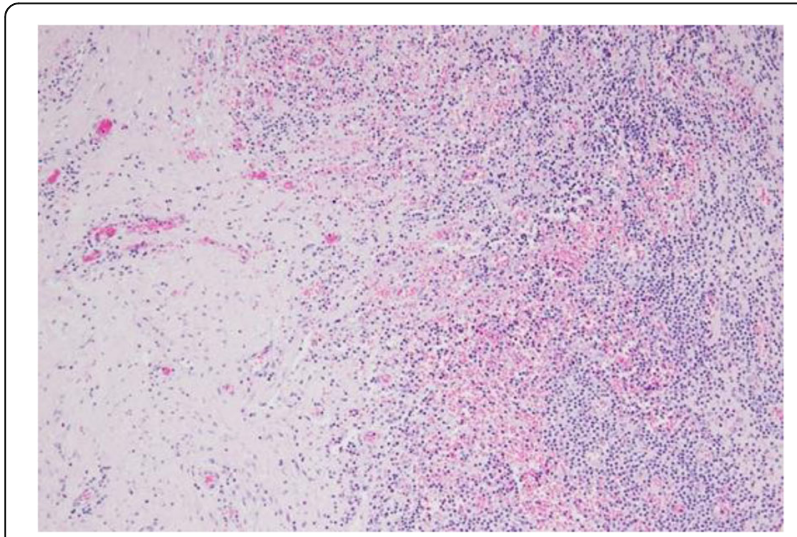

Fig. 6 Histopathological diagnosis of the surgical specimen. Neutrophil-based inflammatory cell infiltration and inflammatory granulation of the tissue resolution magnetic resonance imaging (MRI), which was useful not only for diagnosis but also for identifying landmarks in surgery [10]. Silverman et al. reported that FNA was also useful in the diagnosis of SBA [11]. As for patient 2, the suction of abscess itself leads to the diagnosis of SBA. For the treatment of SBA, total resection of the abscess, including the effected ducts and the formation of an inverted nipple, are the recommended surgical procedures [12-14]. We frequently encounter female cases of SBA, and a large number of cases have been reported in the literature [14]. Breast abscesses are roughly divided into puerperal and nonpuerperal. Most of the nonpuerperal breast abscesses are reported as SBA (86.7\% calculated from reference [14]). If the tumor is present under the areola of the nipple, SBA should be taken into consideration. In male patients, diagnoses by image findings are difficult to perform. Therefore, it is necessary to firmly diagnose SBA from malignant tumors with pathological methods such as FNA and CNB. To our knowledge, there have been only nine reports of male patients with SBA. A summary of the characteristics of the previous nine cases and our two patients are shown in Table $1[11,15-19]$. Most patients were generally under 45 years of age; patient 2 presented herein is an exception to this trend. The disease duration was over 100 days in most cases. FNA was performed in eight cases. CNB was only performed in patient 1 presented herein. All were prediagnosed SBA; five patients underwent resection of their tumors along with the effected ducts. In two cases from the literature, where the disease recurred, both did not have curative operation. For this reason, incisional drainage, which is often performed against breast abscesses, cannot be a curative therapy for SBA. As mentioned above, there is a lack of specific image findings in SBA. In addition, it is difficult to give a diagnosis of SBA only based on the findings of physical examination and imaging test, especially with the two patients we experienced. And we were able to diagnose both cases as SBA before surgery by adding a pathological finding of $\mathrm{CNB}$ and FNA. Regarding patient 1, diagnosed as SBA before surgery, TDR was considered. However, due to the patient's request, he did not prefer TDR. We then decided to carry out a tumor removal procedure under local anesthesia without resection of the effected duct. It has been pointed out that the recurrence rate is high without resection of tumors including effected ducts [14], and this insufficient initial treatment was thus considered to be the cause of recurrence. The two patients we experienced resulted in the contrasting outcomes due to a difference in the surgical procedure, one case recurred and the other did not, which was highly suggestive for future management of SBA. 
Table 1 Summary of reported cases

\begin{tabular}{|c|c|c|c|c|c|c|c|c|c|c|c|c|c|c|}
\hline \multirow[t]{2}{*}{ Case } & \multirow[t]{2}{*}{ Age } & \multirow[t]{2}{*}{ DM } & \multirow[t]{2}{*}{ SM } & \multirow{2}{*}{$\begin{array}{l}\mathrm{DD} \\
\text { (day) }\end{array}$} & \multirow{2}{*}{$\begin{array}{l}\text { DIA } \\
(\mathrm{mm})\end{array}$} & \multirow[t]{2}{*}{ FNA } & \multirow[t]{2}{*}{ CNB } & \multirow[t]{2}{*}{ MC } & \multirow[t]{2}{*}{$\mathrm{MO}$} & \multirow{2}{*}{$\begin{array}{l}\text { Preoperative } \\
\text { diagnosis }\end{array}$} & \multicolumn{2}{|c|}{ Treatment } & \multirow[t]{2}{*}{ SQ } & \multirow[t]{2}{*}{$\operatorname{Rec}$} \\
\hline & & & & & & & & & & & $A B$ & Surgical method & & \\
\hline 1 & 38 & & & 7 & 40 & + & - & + & ND & Breast abscess & + & Incision and drainage & & \\
\hline 2 & 45 & & & 365 & & + & - & & & Subareolar abscess & + & Resection of tumor including ducts & + & - \\
\hline 3 & 37 & & & 240 & & + & - & & & Subareolar abscess & - & NG & & \\
\hline 4 & 42 & - & & 730 & 10 & + & - & & & Subareolar abscess & - & NG & & \\
\hline 5 & 17 & & & 2 & 10 & + & - & & & Subareolar abscess & & Resection of tumor including ducts & & \\
\hline 6 & 41 & & + & 180 & 10 & - & - & & & Subareolar abscess & & Resection of tumor including ducts & + & - \\
\hline 7 & 39 & & & 180 & 8 & - & - & & & Subareolar abscess & + & Resection of tumor including ducts & - & - \\
\hline 8 & 45 & - & & 150 & 15 & + & - & + & ND & Subareolar abscess & + & Aspiration drainage & & + \\
\hline 9 & 27 & & & 7 & 100 & + & - & + & SA & Subareolar abscess & & Incision and drainage & & \\
\hline Patient 1 & 38 & - & + & 30 & 16 & - & + & + & ND & Subareolar abscess & - & Simple tumorectomy & - & + \\
\hline Patient 2 & 65 & + & + & 90 & 20 & + & - & - & ND & Subareolar abscess & + & Resection of tumor including ducts & - & - \\
\hline
\end{tabular}

$D M$ diabetes mellitus, $S M$ smoking history, $D D$ disease duration, DIA diameter, SQ squamous metaplasia of the surgical specimen, $M C$ microbiological culture, $M O$ microorganism, $A B$ antibiotics, Rec recurrence, ND not detected, SA Staphylococcus aureus, NG not given

\section{Conclusions}

Although SBA in male is very rare, it is important to consider it in the differential diagnosis of breast tumors in male patients. Importantly, cytological and pathological analyses are useful for preoperative diagnosis. And to prevent recurrence of the disease, complete resection of the effected duct along with the tumor was recommended essential as derived from previous reports.

\section{Abbreviations}

CNB: Core needle biopsy; FNA: Fine needle aspiration; MRI: Magnetic resonance imaging; SBA: Subareolar breast abscess; TDR: Tumor and duct resection

\section{Authors' contributions}

TK, SO, CS, and IT performed the operations, and TK and NF collected the patient data. TK, NF, and IT wrote the manuscript. TO, HT, and TM performed the literature search. All authors read and approved the final manuscript.

\section{Consent for publication}

Oral informed consent was obtained from both the patients for the publication of this case report and the accompanying images.

\section{Competing interests}

The authors declare that they have no competing interests.

\section{Publisher's Note}

Springer Nature remains neutral with regard to jurisdictional claims in published maps and institutional affiliations.

\section{Author details}

${ }^{1}$ Department of Surgery, Jikei University Daisan Hospital, 4-11-1, Izumihoncho, Komae City, Tokyo 201-8601, Japan. ²Department of Surgery, Kawaguchi Municipal Medical Center, Saitama, Japan. ${ }^{3}$ Department of Respiratory, Breast and Endocrine Surgery, Jikei University School of Medicine, Tokyo, Japan.
Received: 21 August 2017 Accepted: 3 December 2017

Published online: 19 December 2017

\section{References}

1. Zuska JJ, Crile G Jr, Ayres WW. Fistulas of lactiferous ducts. Am J Surg. 1951; 81:312-7. https://doi.org/10.1016/0002-9610(51)90233-4.

2. Habif DV, Perzin KH, Lipton R, Lattes R. Subareolar abscess associated with squamous metaplasia of lactiferous ducts. Am J Surg. 1970;119:523-6. https://doi.org/10.1016/0002-9610(70)90167-4.

3. Kilgore AR, Fleming R. Abscesses of the breast; recurring lesions in the areolar area. Calif Med. 1952;77:190-1.

4. Maier WP, Berger A, Derrick BM. Periareolar abscess in the nonlactating breast. Am J Surg. 1982;144:359-61. https://doi.org/10.1016/00029610(82)90020-4

5. Kasales CJ, Han B, Smith JS Jr, Chetlen AL, Kaneda HJ, Shereef S. Nonpuerperal mastitis and subareolar abscess of the breast. AJR Am J Roentgenol. 2014;202:W133-9. https://doi.org/10.2214/AJR.13.10551.

6. Atkins HJ. Mammillary fistula. Br Med J. 1955;2:1473-4. https://doi.org/10. 1136/bmj.2.4954.1473

7. Gollapalli V, Liao J, Dudakovic A, Sugg SL, Scott-Conner CE, Weigel RJ. Risk factors for development and recurrence of primary breast abscesses. J Am Coll Surg. 2010;211:41-8. https://doi.org/10.1016/j. jamcollsurg.2010.04.007.

8. Bundred NJ, Dover MS, Coley S, Morrison JM. Breast abscesses and cigarette smoking. Br J Surg. 1992;79:58-9. https://doi.org/10.1002/bjs.1800790121.

9. Tan H, Li R, Peng W, Liu H, Gu Y, Shen X. Radiological and clinical features of adult non-puerperal mastitis. Br J Radiol. 2013;86:20120657. https://doi. org/10.1259/bjr.20120657.

10. Fu P, Kurihara Y, Kanemaki Y, Okamoto K, Nakajima Y, Fukuda M, et al. Highresolution MRI in detecting subareolar breast abscess. Am J Roentgenol. 2007:188:1568-72. https://doi.org/10.2214/AJR.06.0099.

11. Silverman JF, Raso DS, Elsheikh TM, Lannin D. Fine-needle aspiration cytology of a subareolar abscess of the male breast. Diagn Cytopathol. 1998;18:441-4. https://doi.org/10.1002/(SICI)1097-0339(199806)18:6<441::AIDDC11>3.0.CO;2-H

12. Patey $\mathrm{DH}$, Thackray AC. Pathology and treatment of mammary-duct fistula. Lancet. 1958;2:871-3. https://doi.org/10.1016/S0140-6736(58)92304-3.

13. Yanai A, Hirabayashi S, Ueda K, Okabe K. Treatment of recurrent subareolar abscess. Ann Plast Surg. 1987;18:314-8. https://doi.org/10.1097/00000637198704000-00008.

14. Versluijs-Ossewaarde FN, Roumen RM, Goris RJ. Subareolar breast abscesses: characteristics and results of surgical treatment. Breast J. 2005:11:179-82. https://doi.org/10.1111/j.1075-122X.2005.21524.x.

15. Sinha RK, Sinha MK, Gaurav K, Kumar A. Idiopathic bilateral male breast abscess. BMJ Case Rep. 2014;2014 https://doi.org/10.1136/bcr-2013-202169. 
16. López-Ríos F, Dhimes P, de Agustín PP. Subareolar abscess of the breast in a male. A report of two cases with fine needle aspiration cytology diagnosis. Acta Cytol. 1997;41:1819-22.

17. Rajaram ST, Kini H, Rau AR, Pai RR. Subareolar abscess in the male breast. Diagn Cytopathol. 2008;36:766-7. https://doi.org/10.1002/dc.20910.

18. Johnson SP, Kaoutzanis C, Schaub GA. Male Zuska's disease. BMJ Case Rep. 2014;2014:bcr2013201922. https://doi.org/10.1136/bcr-2013-201922.

19. Aiyappan SK, Ranga U, Veeraiyan S. Idiopathic subareolar breast abscess in a male patient. J Clin Diagn Res. 2015;9:TJ01. https://doi.org/10.7860/JCDR/ 2015/11258.5404.

\section{Submit your manuscript to a SpringerOpen ${ }^{\circ}$} journal and benefit from:

- Convenient online submission

- Rigorous peer review

- Open access: articles freely available online

- High visibility within the field

- Retaining the copyright to your article

Submit your next manuscript at $\boldsymbol{\sim}$ springeropen.com 